\title{
Thallium determination using catalytic redox reaction between methylene blue and ascorbic acid
}

\author{
${ }^{1 *}$ M. Tabatabaee; ${ }^{1}$ M. R. Shishehbore; ${ }^{2}$ H. Bagheri; ${ }^{1}$ Z. Ebrahimifard \\ ${ }^{1}$ Department of Chemistry, Islamic Azad University, Yazd Branch, Yazd, Iran \\ ${ }^{2}$ Department of Chemistry, Faculty of Science, Islamic Azad University, Takestan Branch, Takestan, Iran \\ Received 17 December 2010; $\quad$ revised 26 March 2010; $\quad$ accepted 17 June 2010; $\quad$ available online 1 September 2010
}

\begin{abstract}
Methylene blue has been proposed as a new analytical reagent for the catalytic spectrophotometric determination of thallium (I). It reacts with ascorbic acid in acidic medium to form a colorless product. Thallium (I) increases the rate of reaction and it can be determined base on its catalytic effect on the reaction. The reagents and manifold variables influences on the sensitivity were investigated and the optimum conditions were established. The reaction has been followed spectrophotometrically by measuring the decrease in the absorbance of methylene blue at $664 \mathrm{~nm}$. A fixed time method of $180.0 \mathrm{~s}$ from initiation of the reaction was used. Under optimum conditions, the proposed method allows the determination of thallium concentrations in the range $3.0-200 \mu \mathrm{g} / \mathrm{mL}$ with a detection limit of $0.09 \mu \mathrm{g} / \mathrm{mL}$. This method is free from of most interference. The results of the proposed method for water samples were comparable with atomic absorption spectroscopy and were found to be in good agreement.
\end{abstract}

Keywords: Catalytic spectrophotometric; Kinetic determination; Thallium determination; Water samples

\section{INTRODUCTION}

Thallium is a trace element that occurs mostly in sulfur containing ores. The common oxidation states of thallium are +1 and +3 , respectively. The determination of thallium (T1) is of importance due to its wide application as a catalyst, in making alloys, optical lenses, jewelry, low temperature thermometers, semiconductors, dyes and pigments and in scintillation counters. Tl compounds have also been used as medicines, rodenticides and insecticides (Jialong et al., 1985; Baxter et al., 1997; Rezaei et al., 2007).

$\mathrm{Tl}$ (I) is highly toxic to the biosphere, its toxicity being even higher than that of $\mathrm{Hg}, \mathrm{Cd}, \mathrm{Pb}$ and $\mathrm{Cu}$. Because of its toxicity, Tl was included in the list of 129 so called "priority pollutants" by the US Environmental Protection Agency. Moreover, Tl (I) is known to replace potassium ions in the activation of enzymes and it is known to have mutagenic, arcinogenic and teratogenic activity (Fergusson, 1990; Leonard and Gerner, 1997; Samarghandi et al., 2007). These risks of thallium impose that its concentration should be systematically measured. Tl concentration in environmental samples is generally quite low. Its

*Corresponding Author Email: tabatabaee45m@yahoo.com Tel.:+98913 3513 497, Fax: +98351 8223313 concentration in surface water usually is in the range of 10 to $100 \mathrm{ng} / \mathrm{L}$ (Lukaszewski et al., 1996), whereas in non-polluted soils lies typically between 0.3 to 0.55 $\mathrm{mg} / \mathrm{kg}$ (Tremel et al., 1997). Because of Tl concentration in environmental samples is very low, threfore the accurate assessment with low detection limit is required.

For this purpose, many separation and preconcentration techniques for the determination of thallium have been proposed including solvent extraction (Shimizu et al., 1998; Wei et al., 2003; Shah et al., 2009; Zvinowanda et al., 2009), single drop extraction, Flotation and solid phase extraction (Chang et al., 2001; Yu et al., 2001; Abou-El-Sherbini et al., 2003; Hosseini and Naseri, 2003; Nameni et al., 2008; Chamsaz et al., 2009 ). However, these methods are laborious and are apt to carry a risk of contamination. A variety of methods have been proposed for the determination of thallium such as inductively coupled plasma (Miyazaki et al., 1992), inductively coupled plasma-mass spectroscopy (Takeda et al., 2001; Wolf et al., 2005), atomic absorption spectroscopy (Carpenter, 1981; Silva et al., 2004), X-ray fluorescence (Mihajlovic and Stafilov, 1998), electroanalytical methods (Ciszewski et al., 1997; Shams and Yekehtaz, 2002; 
Hassanien et al., 2003; Dong et al., 2006; Lee et al., 2008) and spectrphotometry (Namboothiri et al., 1991). Most of these methods are disadvantageous in terms of cost and instruments used in routine analysis (Gong et al., 2010).

The availability of spectrophotometric apparatus and reagents and the simplicity of analytical procedures make the technique very attractive for a wide range of determinations.

Among the methods most commonly used, catalytic kinetic analysis has many advantages such as high sensitivity, good selectivity and rapidity, needing only expediency operation and simple equipments have made catalytic kinetic methods an attractive analytical tool for heavy metal determinations (Abdel-Ghani and Elchaghaby, 2007; Abdel-Ghani et al., 2009). There is no paper have been reported for the determination of trace amounts of thallium based on its catalytic effect on the oxidation or reducation of compounds (Chen et al., 2009). In the present work, the application of methylene blue ascorbic acid indicator reaction to the catalytic spectrophotometric determination of traces of thallium (I) has been described. This study was carried out in Yazd province of Iran in year 2008.

\section{MATERIALS AND METHODS}

All chemicals used were of analytical reagents grade. Deionized water was used throughout. A stock solution of $1000 \mathrm{mg} / \mathrm{L}$ thallium (I) ion was prepared by dissolving the appropriate amounts of thallium nitrate(Merck, Darmstadt Germany) in $1 \% \mathrm{HNO}_{3}$. Working standard solutions were prepared freshly at various concentrations by diluting the stock standard solution with distilled water. Methylene blue (MB) solution $\left(2.0 \times 10^{-4} \mathrm{M}\right)$ was prepared by directly dissolving $0.0355 \mathrm{~g}$ of $\mathrm{MB}$ in water and diluting to 500 $\mathrm{mL}$ in a volumetric flask. The MB solution was stored in dark at $4{ }^{\circ} \mathrm{C}$ and is prepared every month. Ascorbic acid solution of $2.0 \times 10^{-2} \mathrm{M}$ was prepared by dissolving $0.1762 \mathrm{~g}$ of its powder in appropriate amount of water and diluting to $100 \mathrm{~mL}$. This solution was always freshly prepared. Sulfuric acid solution $(0.4 \mathrm{M})$ was prepared by directly dissolving $5.43 \mathrm{~mL}$ of sulfuric acid concentrated ( $a=98 \%$ and $d=1.84 \mathrm{~g} / \mathrm{mL}$ ) in appropriate of water and this mixture was diluted to $250 \mathrm{~mL}$ after cooling. Sodium nitrate solution $3 \mathrm{M}$ was prepared by dissolving its desired amount in water and diluting to $50 \mathrm{~mL}$.

\section{Apparatus}

A Shimadzu Model 160-A UV-VIS spectrophotometer equipped with a quartz cell of $1 \mathrm{~cm}$ path length was used for the absorption spectra and the absorbance measurements. A thermostat (Tokyo Rikakika LTD UA-1) water bath was used to keep the temperature of all solutions at the working temperature $\left(25 \pm 0.1^{\circ} \mathrm{C}\right)$. A stop-watch was used for recording the reaction time.

\section{Procedure}

Except the catalyst concentration, which was varied, a set of optimized concentrations of the other reagents was judiciously chosen for analytical procedure after a detailed spectrophotometric kinetic study of the indicator reaction that was verified in this study. The concentration of the reactants and other conditions were selected under which the catalytic effect of thallium (I) showed maximum sensitivity. All the working solutions were thermostated at $25.0 \pm 0.1^{\circ} \mathrm{C}$ for $30 \mathrm{~min}$. After thermal equilibrium was established, in a $10 \mathrm{~mL}$ volumetric flask, $1.0 \mathrm{~mL}$ of $2.0 \times 10^{-4} \mathrm{M}$ methylene blue solution, $1.0 \mathrm{~mL}$ of $0.4 \mathrm{M} \mathrm{H}_{2} \mathrm{SO}_{4}$, then a known volume of thallium solution were placed. The solution was diluted to $c a$. $8 \mathrm{~mL}$ with water. Then 1.2 $\mathrm{mL}$ of ascorbic acid solution was added to the reaction mixture, followed by dilution to $10 \mathrm{~mL}$ with water. Time was measured just after the addition of the ascorbic acid solution. After thorough mixing a portion of this solution was transferred to a cuvette kept in the temperature controlled cell compartment. The decrease in absorbance methylene blue by ascorbic acid in acidic medium was monitored using the "fixed time procedure" by measuring the change in absorbance at $664 \mathrm{~nm}$ for the first 30-180 s from the start of the reaction.

\section{RESULTS AND DISSCUSSION}

In the presence of traces of $\mathrm{Tl}(\mathrm{I})$, methylene blue is reduced by ascorbic acid in acidic media. This reaction proceeds slowly in the absence of thallium as a catalyst. The decrease in the absorbance, i.e. decrease in the concentration of thallium was measured at $664 \mathrm{~nm}$.

\section{Optimization of reaction variables}

The reaction variables were optimized in order to maximize the sensitivity and precision of the proposed catalytic kinetic method. The effects of reagents concentration, ionic strength, temperature and time on the reaction rate were studied, where 
each variable was changed in turn keeping all other constant. The optimum conditions used for the final working procedure in order to obtain best figures of merit.

\section{Effects of reagent concentrations}

The effect of methylene blue concentration on the catalyzed and uncatalyzed reactions was monitored in the range of $1.0 \times 10^{-5}$ to $3.0 \times 10^{-5} \mathrm{M}$. A limited range owing to the high molar absorptivity of the dye should be used to provide an absorbance in the range of minimum photometric error. According to the results, $2.0 \times 10^{-2} \mathrm{M}$ methylene blue was selected as the optimum working concentration. The effect of sulphuric acid concentration on the analytical signal (sensitivity) was studied in the range of $4.0 \times 10^{-3}$ to $8.0 \times 10^{-2} \mathrm{M}$ under the optimum methylene blue concentration. The rate of catalyzed reaction increased linearly with increasing sulphuric acid concentration to $4.0 \times 10^{-2}$, but the uncatalyzed reaction shows a lower increase. Higher concentrations of $\mathrm{H}_{2} \mathrm{SO}_{4}$ caused a decrease in the rate of the reaction. At still higher concentration, the rate decreases. This decrease in rate at higher acidic condition may be attributed to protonation of methylene blue, which might stop oxidation or make oxidation quiet difficult to occur (Fig. 1).

The effect of concentration of ascorbic acid on the rate of the blank and the catalyzed reactions was investigated. As can be seen from Fig. 2, the difference rate of catalyzed and blank reactions increased with increasing reagent concentration up to $0.0024 \mathrm{M}$, but leveled off at higher concentrations. Therefore, $0.0024 \mathrm{M}$ was chosen as the optimum concentration.

The effect of ionic strength on the reaction rate was also investigated. The ionic strength was varied using $\mathrm{NaNO}_{3}$ solution. Variation in the ionic strength did not affect the performance of the catalytic method.

According to the results, this parameter had no effect on the reaction rate. The temperature of the solution mixture was varied over the range $20-45^{\circ} \mathrm{C}$. An increase in temperature caused an increase in the rate of both catalyzed and uncatalyzed reactions. However, the rate of the blank reaction increased much faster with increase in temperature causing a net decrease in the signal-to-blank ratio. Thus, $25^{\circ} \mathrm{C}$ was chosen as the optimum temperature for thallium determination. The optimized time was found by

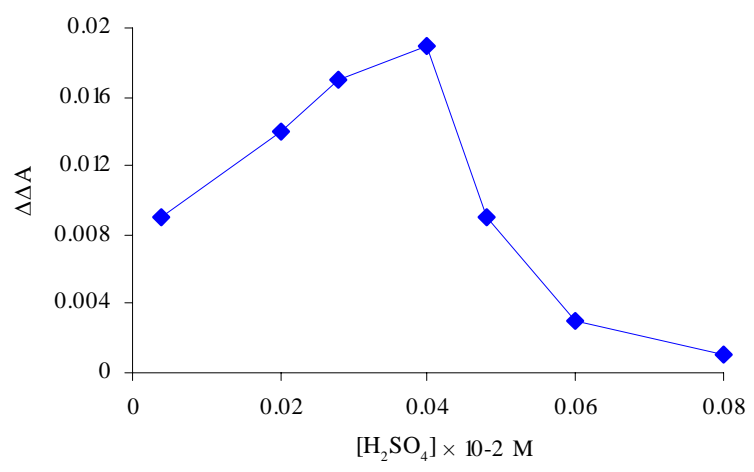

Fig. 1: Effect of sulphuric acid concentration. Conditions: MB, $2.0 \times 10^{-5} \mathrm{M}$; Ascorbic acid, $2.0 \times 10^{-3} \mathrm{M}$; and temperature of $25.0^{\circ} \mathrm{C}$.

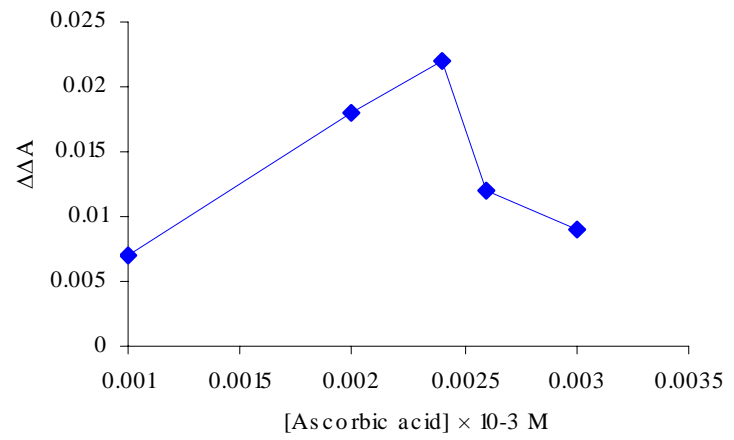

Fig. 2: Effect of ascorbic acid concentration. Conditions: MB, $2.0 \times 10^{-5} \mathrm{M}$; Sulphuric acid, $0.4 \mathrm{M}$ and temperature of $25.0^{\circ} \mathrm{C}$

measuring the absorbance and changing in it during 15 - $270 \mathrm{~s}$ after the initiation of reaction. The reaction rate increase up to $180 \mathrm{~s}$. At still higher time, the rate is almost constant, thus $180.0 \mathrm{~s}$ was selected optimum.

\section{Calibration and analytical parameters}

Under the optimum experimental conditions mentioned above, there was a linear relationship between the difference of absorbance change of the catalyzed and uncatalyzed reactions $\left(\Delta \Delta \mathrm{A}=\Delta \mathrm{A}_{\mathrm{s}}-\Delta \mathrm{A}_{\mathrm{b}}\right.$, $\Delta \mathrm{A}_{\mathrm{s}}=$ difference of absorbance of the catalyzed reaction and $\Delta \mathrm{A}_{\mathrm{b}}=$ difference of absorbance of the uncatalyzed reaction) during a fixed time of $15-180 \mathrm{~s}$ and thallium (I) concentration in the ranges of 3.0-20 $\mu \mathrm{g} / \mathrm{mL}$ and $20-200 \mu \mathrm{g} / \mathrm{mL}$. The correlation coefficient (r) was 0.9986 for the first part of linear dynamic range and its regression equation was $\Delta \Delta \mathrm{A}=0.0015[\mathrm{Tl}(\mathrm{I})]+$ 0.0036 . The regression equation was $\Delta \Delta \mathrm{A}=0.0001[\mathrm{Tl}$ 
(I) $]+0.0237$ for the second part and its correlation coefficient (r) was 0.9991 . The detection limit was determined to be $0.9 \mu \mathrm{g} / \mathrm{mL}$ according to IUPAC definition (Irving et al., 1978). The relative standard deviation for eleven replicate determinations of 3, 20 and $160 \mu \mathrm{g} / \mathrm{mL}$ thallium were $1.9 \%, 2.4 \%$ and $0.9 \%$, respectively. Compared with other methods mentioned in previous section, the sensitivity of this proposed method was very high.

\section{Interferences study}

To study the selectivity of the proposed method, the influence of foreign ions on the reaction rate in the presence of Tl (I) at optimum conditions was studied. The tolerance limit was defined as the concentration of the added ion causing not more than $\pm 3 \%$ relative error for the determination of $20 \mu \mathrm{g} / \mathrm{mL}$ of thallium. The results are summarized in Table 1, which clearly indicates that most common ions do not interfere with the catalytic determination.

Table 1: Effect of various interfering ions for the determination of $20.0 \mu \mathrm{g} / \mathrm{mL} \mathrm{Tl}(\mathrm{I})$

\begin{tabular}{lc}
\hline Tolerance limit & $\begin{array}{l}\text { Interfering species } \\
\text { Interfering species/(Tl (I) }\end{array}$ \\
\hline $\mathrm{Li}^{+}, \mathrm{Na}^{+}, \mathrm{K}^{+}, \mathrm{Ba}^{+2}, \mathrm{Ca}^{+2}, \mathrm{NH}_{4}^{+}$ & \\
$\mathrm{Ni}^{+2}, \mathrm{Cu}^{+2}, \mathrm{Zn}^{+2}$ ' $\mathrm{Co}^{+2}$ & \\
$\mathrm{CO}_{3}^{-2}, \mathrm{CH}_{3} \mathrm{CO}_{2}^{-}, \mathrm{HPO}_{4}^{-2}, \mathrm{PO}_{4}^{-3}$ & \\
$\mathrm{NO}_{3}^{-}, \mathrm{SO}_{4}^{-2}, \mathrm{~F}^{-}, \mathrm{Cl}^{-}, \mathrm{Br}^{-}, \mathrm{I}^{-}$ & 1000 \\
$\mathrm{Hg}^{+2}$ & 600 \\
$\mathrm{C}_{2} \mathrm{O}_{4}^{-2}, \mathrm{SCN}^{-}, \mathrm{ClO}_{3}^{-}$ & 500 \\
$\mathrm{Mn}^{+2}$ & 50 \\
\hline
\end{tabular}

Table 2: Determination of thallium $(\mu \mathrm{g} / \mathrm{mL})$ in water samples

\begin{tabular}{lcrcrrr}
\hline \multicolumn{7}{c}{ Proposed method } \\
Samples & $\begin{array}{c}\text { AAS } \\
\text { Method }\end{array}$ & Detected & Added & Found & $\begin{array}{c}\text { Recovery } \\
(\%)\end{array}$ & $\begin{array}{c}\text { RSD \% } \\
(\mathrm{n}=10)\end{array}$ \\
\hline River water & 104 & 106 & 20 & 125.7 & 98.5 & 0.63 \\
Tap water & 28.5 & 30 & 10 & 40.1 & 101 & 0.71 \\
Sea water & 13.2 & 13.4 & 10 & 23.3 & 99 & 0.87 \\
Boiler water & - & - & 10 & 9.8 & 98 & 0.98 \\
\hline
\end{tabular}

\section{Application}

To evaluate the analytical applicability of the method, the recommended procedure was applied to the determination of thallium (I) in water samples. The samples collected from different sources were filtered. Analysis of water samples for determination of Tl (I) ion content was carried out as follows: 250 $\mathrm{mL}$ of river water or tap water was poured in a beaker and $10 \mathrm{~mL}$ concentrated $\mathrm{HCl}$ was added. While stirring, it heated to reach its volume to one tenth. After adjustment of experimental conditions to desired values the spectrophotometric experiment was performed according to general described procedure. In view of the unknown composition of environmental water samples, the same equivalent portions of each such samples were analyzed for thallium content; the recoveries in both the "spiked" (added to the samples before the mineralization or dissolution) and the "unspiked" samples are in good agreement. Results are described in Table 2. The proposed method was applied and achieved recoveries varying from 99.5 to $100.2 \%$, which demonstrated that the used method had a good accuracy. As seen, the results of ten analyses of each sample obtained by the proposed method and atomic absorption spectrometry (AAS) are in satisfactory agreement. It proved that the method can be used for thallium determination in water samples.

\section{CONCLUSION}

The proposed method was applied to determine thallium by methylen blue chromogenic reagent, without the need for extraction, preconcentration and pre-separation. It offers advantages like reliability and reproducibility in addition to its simplicity and suffers from less interference. It has been successfully applied to the determination of thallium in real samples with satisfactory results. Comparison of the proposed method for the determination of thallium (I) over the

Table 3: Comparison of proposed method for the determination of thallium(I) with the recently published pectroscopic methods

\begin{tabular}{|c|c|c|c|c|}
\hline Reaction system & $\begin{array}{c}\text { Dynamic range } \\
(\mathrm{mol} / \mathrm{L})\end{array}$ & $\begin{array}{l}\text { Detection limit } \\
(\mathrm{mol} / \mathrm{L})\end{array}$ & $\begin{array}{l}\text { Precision } \\
(\% \text { RSD })\end{array}$ & Reference \\
\hline Iodide-Rhodamine B & $0.8 \times 10^{-4}-8.0 \times 10^{-4}$ & $4.7 \times 10^{-8}$ & $3.34^{\mathrm{a}}$ & Hosseini and Naseri, 2003 \\
\hline 4-(4'-N,N-Dimethylaminophenyl) Urazole-Tl & $8.0 \times 10^{-8}-3.0 \times 10^{-5}$ & $5.0 \times 10^{-8}$ & $2.75^{\mathrm{b}}$ & Rezaei et al., 2007 \\
\hline Methylene Blue-Ascorbic acid & $1.47 \times 10^{-5}-9.78 \times 10^{-4}$ & $4.47 \times 10^{-7}$ & $1.9^{\mathrm{c}}$ & Proposed method \\
\hline
\end{tabular}


recently published spectroscopic methods along with the reaction system, linear dynamic range (LDR), detection limit (DL) and precision (\% RSD) of the methods are summarized in Table 3 .

\section{ACKNOWLEDGMENTS}

The authors are grateful to Islamic Azad University, Yazd Branch, for the support of this work

\section{REFERENCES}

Abdel-Ghani, N. T.; Elchaghaby, G. A., (2007). Influence of operating conditions on the removal of $\mathrm{Cu}, \mathrm{Zn}, \mathrm{Cd}$ and $\mathrm{Pb}$ ions from wastewater by adsorption. Int. J. Environ. Sci. Tech., 4 (4), 451-456 (6 pages).

Abdel-Ghani, N. T.; Hegazy, A. K.; El-Chaghaby, G. A., (2009). Typha domingensis leaf powder for decontamination of aluminium, iron, zinc and lead: Biosorption kinetics and equilibrium modeling. Int. J. Environ. Sci. Tech., 6 (2), 243 248 (6 pages)

Abou-El-Sherbini, K. S.; Mostafa, G. A. E.; Hassanien, M. M., (2003). A new selective chromogenic reagent for the spectrophotometric determination of thallium (I) and (III) and its separation using flotation and the solid-phase extraction on polyurethane foam. Anal. Sci., 19 (9), 1269-1275 (7 pages).

Baxter, M. J.; Crews, H. M.; Dennis, M. J.; Goodall, I.; Anderson, D., (1997). The determination of the authenticity of wine from its trace element composition. Food Chem., 60 (3), 443-450 (8 pages).

Carpenter, R. C., (1981). The determination of cadmium, copper, lead and thallium in human liver and kidney tissue by flame atomic absorption spectrometry after enzymatic digestion. Anal. Chim. Acta, 125, 209-213 (5 pages).

Chamsaz,. M.; Arbab-Zavar, M. H.; Darroudi, A.; Salehi, T., (2009). Preconcentration of thallium (I) by single drop microextraction with electrothermal atomic absorption spectroscopy detection using dicyclohexano-18-crown-6 as extractant system. J. Hazard. Mat., 167 (1-3), 597-601 (5 pages).

Chang, X. J.; Su, Q. Q.; Wei, X. J.; Wang, B. T., (2001). Determination of thallium in water samples. Mikrochim. Acta, 137, 209-213 (5 pages).

Chen, Z.; Zhang, N.; Zhuo, L.; Tang, B., (2009). Catalytic kinetic methods for photometric or fluorometric determination of heavy metal ions. Microchim. Acta, 164, 311-336 (26 pages).

Ciszewski, A.; Wasiak, W.; Cizewski, W., (1997). Hair analysis. Part 2. Differential pulse anodic stripping voltammetric determination of thallium in human hair samples of persons in permanent contact with lead in their workplace. Anal. Chim. Acta, 343 (3), 225-229 (5 pages).

Dong, H.; Zheng, H.; Lin, L.; Ye, B., (2006). Determination of thallium and cadmium on a chemically modified electrode with Langmuir-Blodgett film of p-allylcalixarene. Sensors \& Actuators B, 115 (1), 303-308 (6 pages).

Fergusson, J. E., (1990). The heavy elements: chemistry, environmental impact and health effects., Pergamon Press., Oxford.

Gong, R.; Li, N.; Cai, W.; Liu, Y.; Jiang, J., (2010). $\alpha-$ Ketoglutaric acid-modified chitosan resin as sorbent for enhancing methylene blue removal from aqueous solutions.
Int. J. Environ. Res., 4 (1), 27-32 (6 pages).

Hassanien, M. M.; Abou-El-Sherbini, K. H. S.; Mostafa, G. A. E., (2003). A novel tetrachlorothallate (III)-PVC membrane sensor for the potentiometric determination of thallium (III). Talanta, 59 (2), 383-392 (10 pages).

Hosseini, M. S.; Naseri, Y., (2003). Determination of thallium(I) by flotation-spectrophotometric method using iodide and rhodamine b. Anal. Sci., 19 (11), 1505-1508 (4 pages).

Irving, H. M.; Freiser, H.; West, T. S., (1978). (Eds.), IUPAC Compendium of Analytical Nomenclature: Definitive Rules. Pergamon Press, Oxford.

Jialong, G.; Gang, G.; Xilin, L.; Tongyue, C., (1985). Spectrophotometric determination of trace amounts of thallium with 7-(4,5-dimethylthiazolyl-2-azo)-8hydroxyquinoline-5-sulphonic acid. Talanta, 32 (11), 1072-1073 (2 pages).

Lee, G. J.; Lee, H. M.; Uhm, Y. R.; Lee, M. K.; Rhee, C. K., (2008). Square-wave voltammetric determination of thallium using surface modified thick-film graphite electrode with Bi nanopowder. Electrochem. Commun., 10 (12), 1920-1923 (4 pages).

Leonard, A.; Gerber, G. B., (1997). Mutagenicity, carcinogenicity and teratogenicity of thallium compounds. Mut. Res., 387, 47-53 (7 pages).

Lukaszewski, Z.; Zembrzuski, W.; Piela, A., (1996). Direct determination of ultratraces of thallium in water by flowinjection differential-pulse anodic stripping voltammetry. Anal. Chim. Acta, 318 (2), 159-165 (7 pages).

Mihajlovic, D.; Stafilov, T., (1998). Determination of thallium in geological samples by X-ray fluorescence spectrometry. X-ray Spectrum., 27, 397-400 (4 pages).

Miyazaki, A.; Sanpei, T.; Tao, H.; Nagase, T., (1992). Determination of trace thallium in natural waters by inductively coupled plasma emission spectrometry combined with solvent extraction. Nippon Kagaku Kaishi. 3, 307-311 (5 pages).

Namboothiri, K. K.; Balasubramanian, N.; Ramakrishna, T. V., (1991). Spectrophotometric determination of thallium after its extraction as an ion-pair of the chloro-complex and pyronine G. Talanta, 38 (8), 945-949 (5 pages).

Nameni, M.; Alavi Moghadam, M. R.; Arami, M., (2008). Adsorption of hexavalent chromium from aqueous solutions by wheat bran. Int. J. Environ. Sci. Tech., 5 (2), 161-168 (8 pages).

Rezaei, B.; Meghdadi, S.; Majidi, N., (2007). Preconcentration of thallium (III) with 2,6-bis (N-phenyl carbamoyl) pyridine on microcrystalline naphthalene prior to its trace determination in human serum spectrophotometrically. Spectrochim. Acta, Part A 67 (1), 92-97 (6 pages).

Samarghandi, M. R.; Nouri, J.; Mesdaghinia, A. R.; Mahvi, A. H.; Nasseri, S.; Vaezi, F., (2007). Efficiency removal of phenol, lead and cadmium by means of UV/TiO2/H2O2 processes. Int. J. Environ. Sci. Tech., 4 (1), 19-25 (7 pages).

Shah, B. A.; Shah, A. V.; Singh R. R., (2009). Sorption isotherms and kinetics of chromium uptake from wastewater using natural sorbent material. Int. J. Environ. Sci. Tech., 6 (1), 77-90 (14 pages).

Shams, E.; Yekehtaz, M., (2002). Determination of trace amounts of thallium by adsorptive cathodic stripping voltammetry with xylenol orange. Anal. Sci., 18 (9), 993996 (4 pages).

Shimizu, T.; Kozawa, S.; Kawaguchi, H.; Shijo, Y., (1998). Determination of ultra traces of thallium in natural waters 
by graphite furnace atomic absorption spectrometry after solvent extraction and back extraction. Nippon Kagaku Kaishi., 4, 247-251 (5 pages).

Silva, A. F.; Borges, D. L. G.; Welz, B.; Vale, M. G. R.; Silva, M. M.; Klassen, A.; Heitman, U., (2004). Method development for the determination of thallium in coal using solid sampling graphite furnace atomic absorption spectrometry with continuum source, high-resolution monochromator and CCD array detector. Spectrochim. Acta Part B, 59 (6) 841 850 (10 pages)

Takeda, K.; Ikushima, S.; Okuzaki, J.; Watanabe, S.; Fujimoto, T.; Nakahara, T., (2001). Inductively coupled plasma mass spectrometric determination of ultra-trace elements in electronic-grade water and chemicals using dulcitol. Anal. Chim. Acta, 426 (1), 105-109 (5 pages).

Tremel, A.; Masson, P.; Garraud, H.; Donald, O. F.; Baize, D.; Mench, M., (1997). Thallium in French agrosystems-II.
Concentration of thallium in field-grown rape and some other plant species. Environ. Pollut., 97, 161-168 (8 pages). Wei, G. T.; Yang, Z.; Chen, C. J., (2003). Room temperature ionic liquid as a novel medium for liquid/ liquid extraction of metal ions. Anal. Chim. Acta, 488 (2), 183-192 (10 pages).

Wolf, S. F.; Unger, D. L.; Friedrich, J. M., (2005). Determination of cosmochemically volatile trace elements in chondritic meteorites by inductively coupled plasma mass spectrometry. Anal. Chim. Acta, 528 (1), 121-128 (8 pages).

Yu, M. Q. ; Tian, W.; Sun, D. W.; Shen, W. B.; Wang, G. P.; Xu, N., (2001). Systematic studies on adsorption of 11 trace heavy metals on thiol cotton fiber. Anal. Chim. Acta, 428 (2), 209-218 (10 pages).

Zvinowanda, C. M.; Okonkwo, J. O.; Shabalala, P. N.; Agyei, N. M., (2009). A novel adsorbent for heavy metal remediation in aqueous environments. Int. J. Environ. Sci. Tech., 6 (3), 425-434 (10 pages).

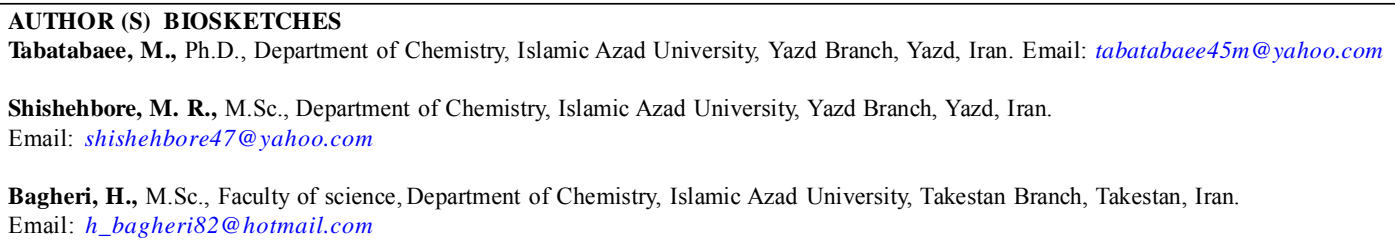

Tabatabaee, M.; Shishehbore, M. R.; Bagheri, H.; Ebrahimifard, Z., (2010). Thallium determination using catalytic redox reaction between methylene blue and ascorbic acid. Int. J. Environ. Sci. Tech., 7 (4), 801-806. 